Journal of Sustainability Perspectives

journal homepage: https://ejournal2.undip.ac.id/index.php/jsp/

\title{
Plan for The Efficient Use and Saving of Water at The Universidad del Norte
}

\author{
Adolfo Meise ${ }^{1 *}$, Alma Lucia Diazgranados ${ }^{2}$, Oscar Álvarez González ${ }^{3}$, Daniel Rincón ${ }^{4}$, Jeniffer \\ Ariza Reino ${ }^{5}$, Cristian Loaiza ${ }^{6}$ \\ 1,2,3,4,5,6 Universidad Del Norte \\ *corresponding author: ameisel@uninorte.edu.co
}

Article Info

Received:

15 March 2021

Accepted:

25 May 2021

Published:

1 August 2021

DOI:

Presented in The $6^{\text {th }}$ International (Virtual) Workshop on UI GreenMetric World University Rankings (IWGM 2020)

\begin{abstract}
Portable water is an essential resource for living, currently there is enough water in the world for this, but its distribution is not adequate in different places or at different seasons of the year. Climatic variations affect the water supply capacity generate economic, social and environmental problems. The commitment of Universidad Del Norte with the environment and its transversally in its missionary functions of teaching, research, and extension crystallize in academic and administrative strategies, complying not only with environmental legislation, but also management with criteria of resource efficiency (Water, energy, air, waste, fauna and flora) promoting environmental education, conservation, respect for nature and long-term sustainability. The foregoing derives from the responsibility that Universidad Del Norte has had with the community in creating a PUEAA - Plan for the efficient use and saving of water, which describes the strategies aimed at the conservation and use of water resources. The following article describes the strategies that the Universidad Del Norte carries out to have a continuous supply of water, guarantee the quality of drinking water for its consumption processes, treat all wastewater resulting from its processes, and finally reuse all water that is finally use in campus gardens.
\end{abstract}

\section{Keyword:}

Wastewater and gray water, PUEAA, campus, biological treatment.

\section{Introduction}

There is a great challenge for all companies that make use of drinking water within their production processes and mainly those that focus their actions on the sustainable use of this water resource, considering it as a finite and vulnerable resource that is affected by factors ranging from population growth, urban progress, effects of climate change, contamination of water sources and the excessive use of the resource, which has led to an imbalance between fresh water sources and the demand for drinking water. We recognize as a superior academic institution that the changes that must be promoted in the efficient use and saving of drinking water must be focused on the technological implementation, 
research and training of our community; in order to materialize these ideals, the following are essential: associations, knowledge, information distribution networks and innovation.

As an institution of higher education, we find ourselves in high ranges of drinking water consumption given our demand for activities related to services, cleaning, laboratories, cafeterias, irrigation and gardening. To illustrate, Bonet et al, (2001) point out that the uses of water in large university centers are similar to the uses that occur in medium-sized cities and that understanding this is important to carry out environmental management processes in institutions. Likewise, in order to promote conservation and efficient use processes in educational centers, Cheng and Hong (2002) establish the ways of using water in primary schools and find that many of these have problems due to their high water consumption due to failures on faulty pipes and installations. With reference to the above, it is mentioned that inappropriate water management is among some factors that intensify the issue. The contribution to the solution of said problem must start from the policies of environmental management, commitments and specific goals in the short and medium term that lead to collective and beneficial results for the institution.

The following article is a contribution to the processes of efficient use and saving of water that are developed in higher education institutions, as well as in processes that are carried out within the environmental management plan at the Universidad del Norte in Puerto Colombia Atlántico.

The Universidad del Norte is geographically located at the coordinates $11^{\circ} 01^{\prime} 05^{\prime \prime} \mathrm{N}$ $74^{\circ} 51^{\prime} 04^{\prime \prime} \mathrm{W}$, it has a total extension of $256,015 \mathrm{~m} 2$ and a built area of $77,309 \mathrm{~m} 2 ; 60.38 \%$ of the area is covered by vegetation in the form of planted forests and gardens, it also has the privilege of being hydrographically surrounded by the Magdalena River (its basin occupies $24 \%$ of the country's continental territory) and the Ciénaga Mallorquín.

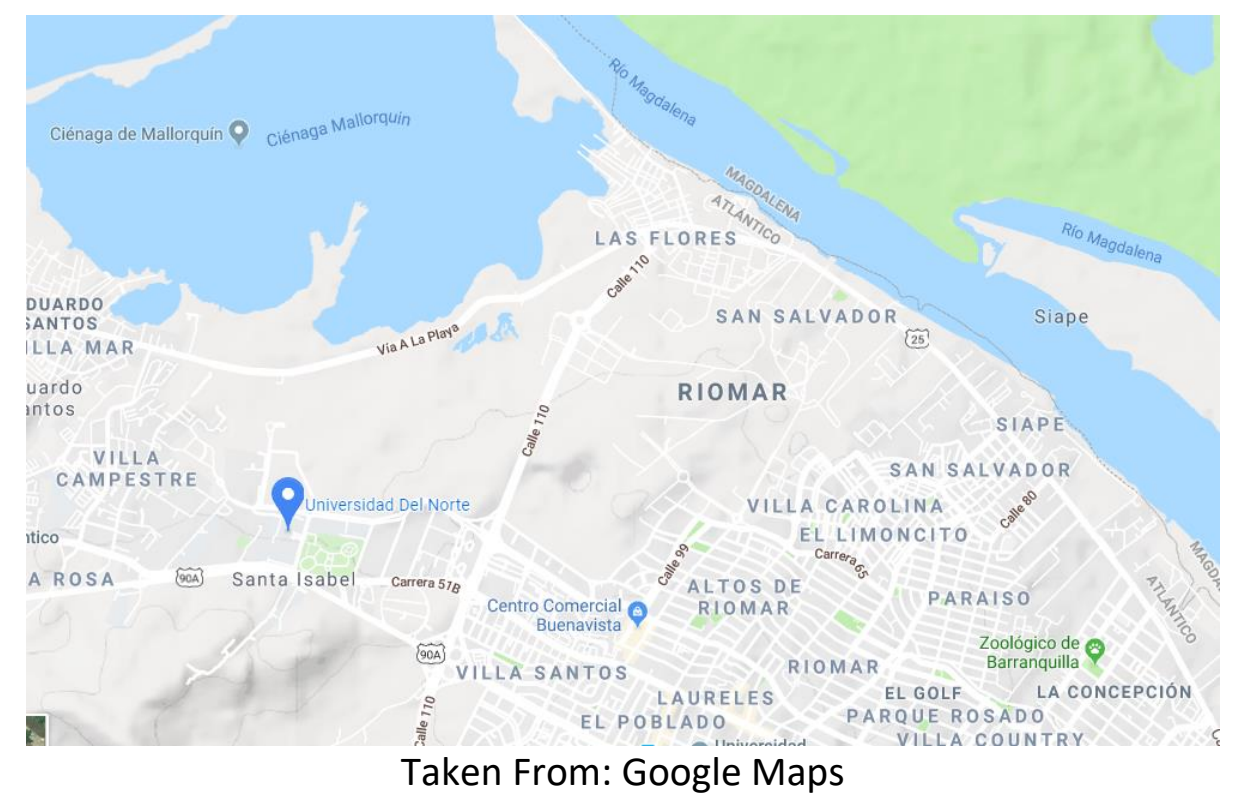

\section{Distribution networks, use of drinking water and reuse of treated water}

The scope of the plan for the efficient use and saving of water of the Universidad del Norte is to unify, define and outline the strategies proposed for the optimization and responsible use of the resource through the integration of human capital and physical infrastructure; the first refers to the community in general that passes through the 
institution making use of the water resource and includes the personnel in charge of ensuring the operation of the system, the second corresponds to the physical storage infrastructure, transport equipment and treatment plants.

The Universidad del Norte has the capacity to store $1000 \mathrm{~m} 3$ of drinking water in 10 underground and elevated containers distributed throughout its extension. The purpose is to guarantee the supply of the fluid in all buildings and supply points in periods of normal operation and in emergency situations that arise with the public service provider. Likewise, having a large drinking water storage capacity makes us responsible for guaranteeing the conditions of potability of the water resource; This activity is carried out through postchlorination systems located in three main distribution tanks to which a disinfectant is applied according to the flow of drinking water that enters the storage container, ensuring the permissible concentration range and therefore the physicochemical and microbiological of drinking water

Among all the processes in which drinking water and other sources of water are used such as rainwater and condensation (the result of the air conditioning process in buildings), those with the greatest use of the resource stand out, production of food in internal restaurants, bathrooms and showers, garden irrigation and maintenance of the physical plant. All these processes generate a continuous liquid discharge that is conducted and homogenized within the internal hydrosanitary network to later be treated in biological wastewater treatment systems and then finally reused in the irrigation of green areas and campus gardens. This allows the resource to be returned to the environment under favorable conditions, leading to reuse in the fertilization of the land due to its high nutrient content, facilitating the growth of vegetation. Added to the above is the great savings in drinking water obtained by replacing the irrigation fluid. See Figure 1.

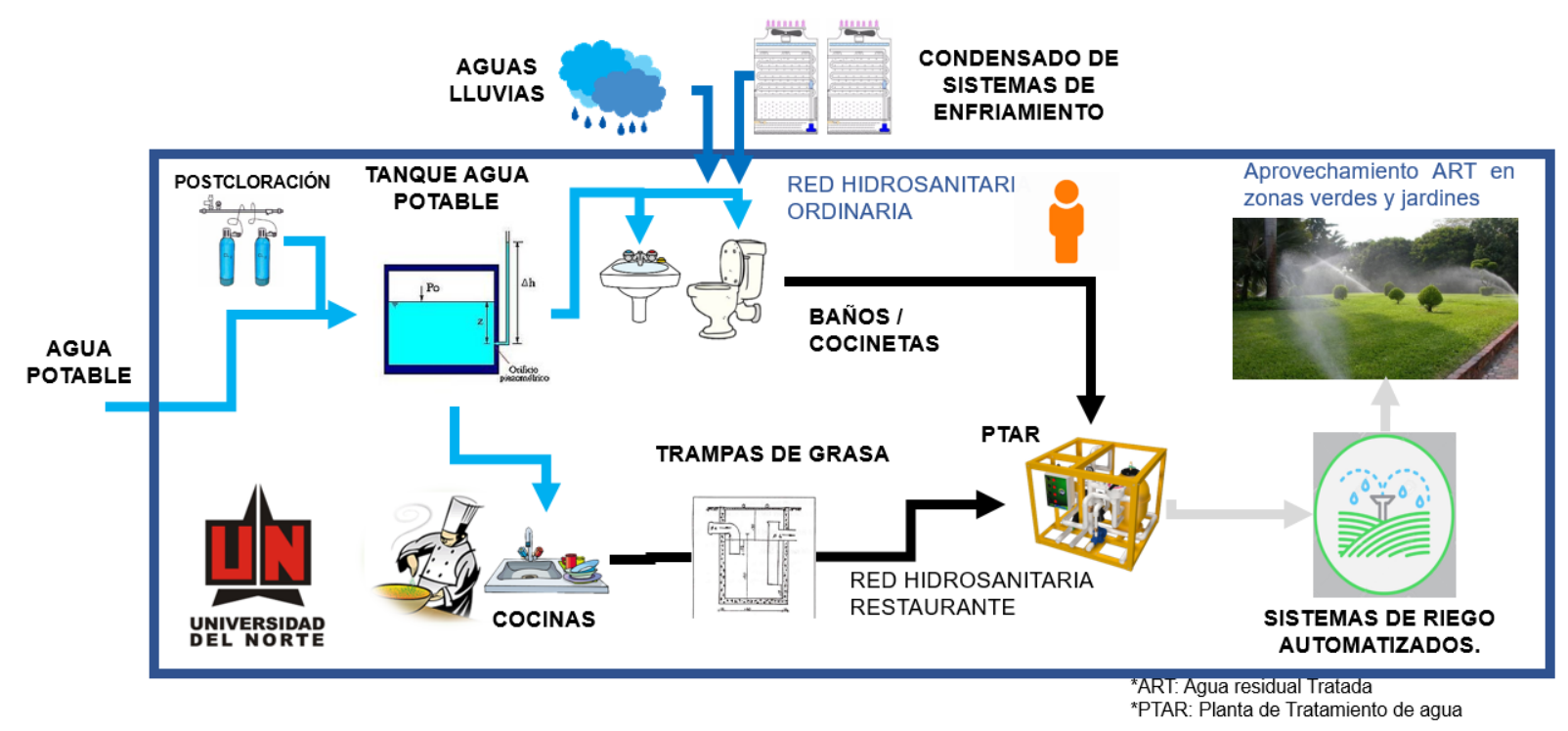

Figure 1. Diagram of Supply and Sanitation Networks Uninorte

\section{Use strategies and efficient and saving of water consumption}

Knowing in detail the operating conditions and infrastructure of the Universidad del Norte, we see ourselves in the obligation as an institution to guarantee the optimal conditions to carry out the efficient use and saving of water through operational strategies, technological training to the community, which will be described in detail: 


\subsection{Post-chlorination system:}

The residual chlorine concentration in drinking water is guaranteed through chlorine injection systems, which in turn ensure the water quality. There is a program of daily verification of residual chlorine with the support of technical teams for storage containers and biweekly verification for drinking water supply points, guaranteeing that the chlorine concentration values handled in the operation comply with the permissible range for water for human consumption.

\subsection{Uninorte Solutions Center:}

Within the technical (software) and operational tools available to the Universidad del Norte, the work of the operational technical staff in charge of identifying, verifying and solving any incident that is related to the deterioration of the physical plant and in turn generate losses and high consumption of water resources. All this management is possible, thanks to a group of people who are in charge of monitoring in real time the consumption behavior of the tanks and the operation of the mechanisms that support the distribution of the fluid.

\subsection{Maintenance of drinking water containers:}

Semi-annual maintenance is carried out on the water tanks, guaranteeing their safety and good condition. Likewise, the drinking water storage tanks have waterproofing membranes and stainless steel covers that guarantee the permanent cleaning of the containers.

\subsection{Potable Water distribution and measurement system:}

Within the facilities there are potable water distribution and pumping systems that ensure the supply of the fluid in the buildings. Likewise, there are consumption meters within the campus which broadcast the information in real time to the servers and monitoring programs.

\subsection{Water-saving systems in bathrooms:}

The University implements systems that save drinking water in faucets and accessories for bathrooms that would guarantee the effective use of the fluid by the community.

\subsection{Community awareness:}

Through environmental simulations, the Universidad del Norte sensitizes its community about the good practices of the good use and saving of drinking water, thus avoiding indiscriminate use of resources and inappropriate dumping within the internal hydrosanitary network of the College.

\subsection{Sustainable Purchases:}

The University developed an investigation to identify the compositions of the chemical products used for the cleaning of the physical plant and the maintenance of gardens in such a way that only the use of environmentally friendly or easily biodegradable products would be standardized.

\subsection{Treatment of Biodegradable Products:}

For the management of fat residues within the internal hydrosanitary networks of the 
kitchens of the restaurants of the North University, a control strategy is carried out through the application of degrading products of this type of residues and a weekly cleaning of the grease retention systems. Thus avoiding the organic overload of the PTARs.

\subsection{Treatment of liquid discharges:}

Within the supervision and operation of the Wastewater Treatment Plant, the verification of the operation conditions is carried out by means of technological equipment that provides information on site of the following parameters: Ph, temp and dissolved oxygen, free chlorine. These data are analyzed and generate improvement actions for the treatment process.

\subsection{Automated irrigation system for green areas and gardens:}

To sustain green areas and gardens at the Universidad del Norte, they use automated irrigation systems capable of efficiently taking advantage of the wastewater treated by the PTARS.

\subsection{Use of condensed water:}

To save the supply of drinking water in sanitary systems, we have an additional source of generation. The heat exchange processes that are carried out in the institution's air conditioning systems, and taking advantage of the high levels of relative humidity that exist in our climate, allow the water vapor contained in our ambient air to be condensed to be reused in particular activities of the physical plant operation.

\section{Conclusion}

The Universidad del Norte is committed to the environment and its transversality meets the criteria of efficiency in the management of water resources, promotes environmental education, conservation of the environment and respect for the legal regulatory framework.

Water is one of the most valuable and vital natural resources on the planet. Aware of this, at Uninorte we implement strategies to promote its efficient use. Different strategies such as treating wastewater on campus and converting it into water suitable for irrigation of fields and gardens.

They also include the installation of taps with push systems and infrared sensors with a percentage of the implementation ranging from $82 \%$ to $98 \%$ for saving water in urinals, toilets and sinks, as well as the automation of almost $90 \%$ of the irrigation systems for green areas.

With the use of condensate water produced by the ice water chillers, it has been possible to reduce the consumption of $12,299 \mathrm{~m} 3$ / year of drinking water.

Due to the reuse of treated water in irrigation systems, the Universidad del Norte was able to save $118,627 \mathrm{~m} 3$ / year of drinking water, this being equivalent to the average consumption of 2601 people during one year.

\section{References}

1. Universidad del Norte. Plan el uso eficiente y ahorro del agua.

2. Romero J., Moré R., Luna A. (2013) Ahorro y uso responsable del agua en el sistema institucional de gestión ambiental SAURA en la Universidad El Bosque.

3. Manco D., Guerrero J., Ocampo Ana (2012) Eficiencia en el consumo de agua de uso 
residencial, Revista ingenierías Universidad de Medellín.

4. Ramírez E. (2017) Formulación de un Plan de Uso Eficiente y Ahorro del Agua, basado en un modelo de proyección de demanda hídrica en la hacienda Cabaña.

5. Trujillo C., Sarmiento J. (2012) Estrategias de uso eficiente y ahorro de agua en centros educativos, caso de estudio, edificio facultad de ciencias ambientales. Universidad tecnológica de Pereira

6. Torres T., (2015) Estrategia para usar racionalmente el agua: experiencia de una entidad de educación técnica industrial, certificada bajo la norma ISO 14001:2004 Universidad Nacional Mayor de San Marcos Lima, Perú.

7. Valencia N., (2015) Estrategias de ahorro y uso eficiente del agua de uso residencial, estudio de caso, corregimiento de san clemente-municipio de guática Risaralda. Universidad Tecnológica de Pereira. 